Published by the University of KwaZulu-Natal

https://journals.ukzn.ac.za/index.php/JICBE

(C) Creative Commons With Attribution (CC-BY)

Journal of Inclusive cities and Built environment. Vol. 2 Issue 1

How to cite: H.H Magidimisha-Chipungu. 2022. Policy Brief- safer City Audit for women. Conference Proceedings for International Symposium on Inclusive-Cities: Achieving Inclusive Cities Through A Multidisciplinary Approach, 2021 28-30 June. Journal of Inclusive cities and Built environment Vol. 2 Issue 1, Pg 87-93.

\title{
POLICY BRIEF- SAFER CITY AUDIT FOR WOMEN
}

\section{By H.H Magidimisha-Chipungu}

Published 31 January 2022

\begin{abstract}
Urbanization is closely linked with increases in economic and social development. Yet in South African cities, alongside all the growth and advancement taking place, progress is undermined by the dearth of safety, resulting from poor planning, security challenges, poor and/ or lack of infrastructure. Consequently, putting both city's inhabitants and visitors in danger, and women, in particular, bear the heaviest brunt of unsafe urban spaces. While the post-apartheid South African cities are open to women, there still exists a gap in their safety and experiences within the same cities.
\end{abstract}

KEY WORDS Safe City, Women, Safety, Inclusive Development, Secondary Cities

Prof Hope Magidimisha-Chipungu: (PhD), SARChl Chair for Inclusive Cities, University of KwaZulu-Natal.

E-mail: magidimishah@ukzn.ac.za 


\section{INTRODUCTION}

Safety can be thought of as physical protection, but it can also be used in the wider sense, speaking to the ability of people to make the choices they consider necessary for their well-being. Safety is a necessary condition for providing life choices to individual people. Life choices are dramatically reduced in contexts of violence, crime, fear, and uncertainty, but equally when social services such as education and health are poor, missing, or difficult to access. Indeed, lower levels of physical safety are almost always present when varied forms of opportunity and service delivery are absent. That is no coincidence. Safety in an urban context then encompasses much more than simply protecting people. It means the development of educational and health structures, recreational venues, the harnessing of local skills, and the facilitation of community-building activities, all whilst taking a gender-responsive approach, recognizing the needs and views of women and girls and men and boys focused on their diversity (looking across a broad spectrum of factors such as age, race, ethnicity, income, (dis)abilities, etc.). When viewed from this perspective, safety has everything to do with inclusive development and thus needs to be strategically integrated into the deployment of resources and interventions. Safety, or the lack thereof, deeply affects women and girls, from their ability to participate and thrive in the economy, to move about freely without fear, to attend school and recreational activities, to access government services, or to feel safe and supported inside their city. The 2030 Agenda also explicitly highlights the promotion of safe, inclusive, and resilient cities (SDG 11). Considering the complexity of the safety in South African cities, its effect on our progress in every other respect, and the interconnected and holistic responses which must be explored, this brief highlight safety of women and lack thereof in six cities, in a bid to aid policy development and the local authorities to put their full might behind improving the safety of women. The audit identified the need for more effective and evidencebased interventions at the local level to strengthen resilience and improve the safety of communities.

\section{METHODOLOGY}

The research team under the SARChI for Inclusive Cities at the University of KwaZulu Natal, School of Built Environments and Developments Studies conducted a City Safety audit in six secondary cities; City of eMalahleni, City of eMfuleni, City of George, City of Motlasane, City of Polokwane and City of uMhlathuze, as shown on the map below, in six different provinces of South Africa within the months September and October 2021. The audit observations were photographed, and opinion polls were fully described, for the benefit of the reader. The audit was conducted at different times of the day, that's morning afternoon, and night, in all cities. The purpose of differentiating and widening the time range for data collection was to ensure the reliability of collected data. The purpose of the City Safety Audit was to estimate and appropriate the degree of safety or lack of it in the aforementioned cities. A guide was used to focus the observations and opinion polls. This guide focused on Street lighting Signage, Footpaths convenience, accessibility and usability, Cleanliness of urban space, Emergency help convenience, informal surveillance and policing, Potential street mugging and proportion of people around, and Street crossing safety features. Thematic analysis was used to reveal and simplify the findings.

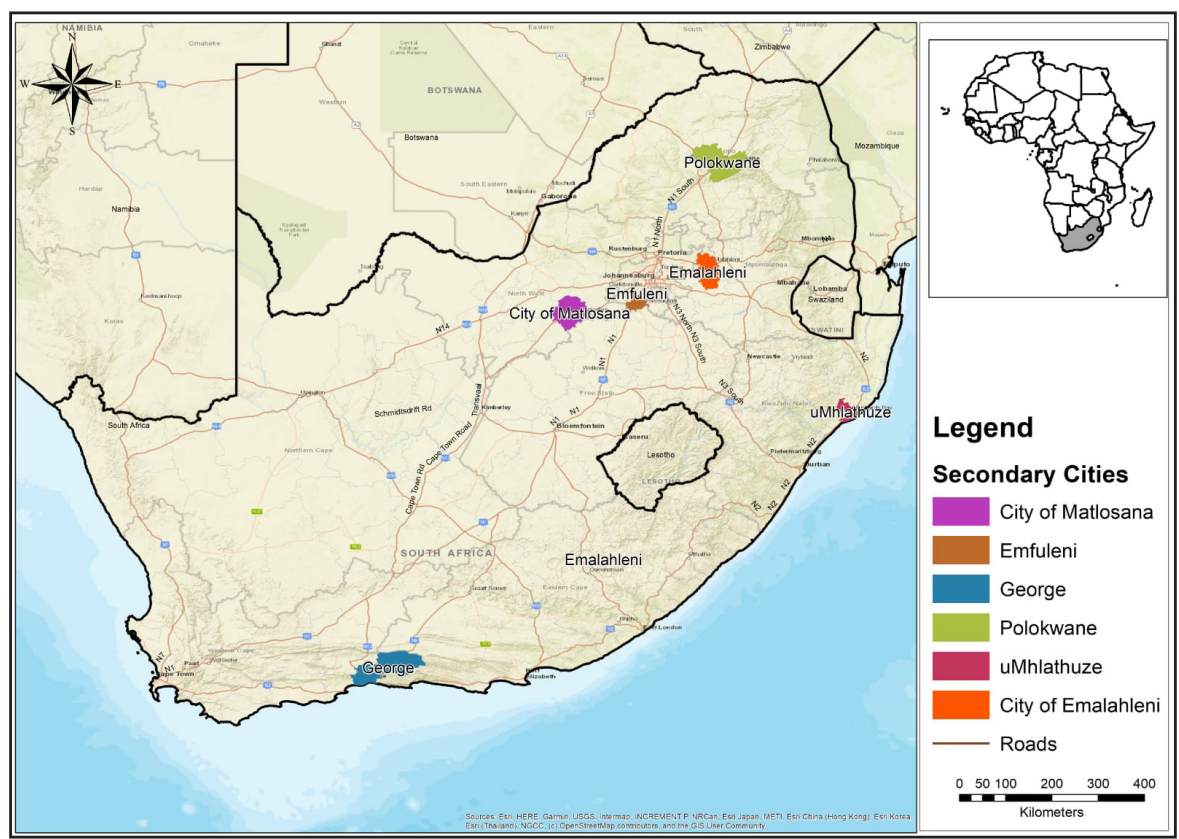

Map showing cities audited. (Prepared by SARChI Chair for Inclusive Cities , 2021)

\section{SUMMARY OF THE FINDINGS}

Findings across the six cities consistently underscored safety challenges that not only render inhabitants unsafe but also compromise their equitable access to essential services and economic participation in the city and also very often reinforce the marginalisation of women and girls. Though the degree of safety or lack thereof differs from one city to another, there are common denominators identified across these cities. 


\section{STREET LIGHTING}

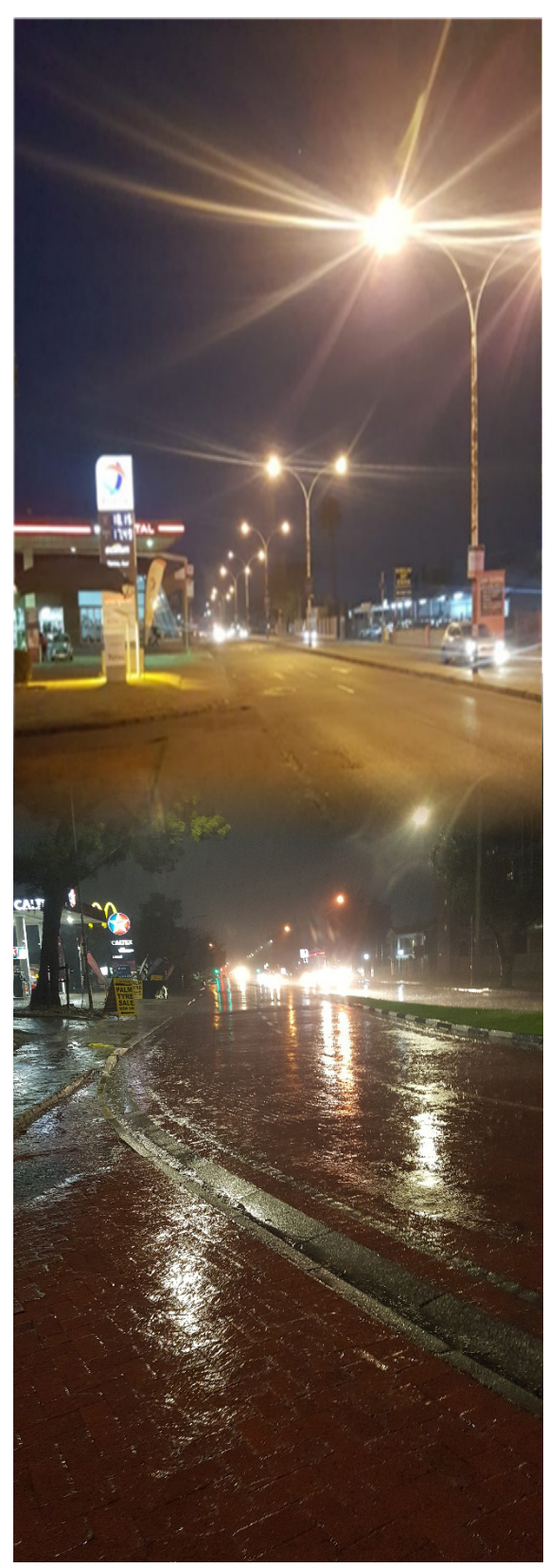

The application of illumination along roads with the primary purpose of improving safety and ease of movement of vehicles and pedestrians during the hours of darkness increases safety by making road features such as road alignment, curbs, footpaths, street furniture, surface condition, other road users and objects that may be on the road visible to both vehicular and pedestrian traffic. If these requirements are met, road accidents and criminal activities in the streets can be substantially reduced.

There is a wide exhibition of irregularities pertaining to street lighting across the streets in most cities. A cautious exception can be given to the city of George; it is doing relatively better than other cities in this regard. In the Central Business Districts of City eMalahleni, eMfuleni, Motlasane, Polokwane, and uMhlathuze, streetlights are unevenly distributed with some lights not working mainly due to lack of maintenance for example this phenomenon is most pronounced in the City of Polokwane. In other cities like eMalahleni, the streetlights in the downtown areas of this city are in a derelict condition - some streets are left with a mere lamp post without lights while some streets have no resemblance of streetlights installations. Safety for women diminishes with nightfall in these parts of the cities. This is also confirmed by a rare sight of women strolling the streets at night in most of these cities. It is a tacit 'rule' that no woman should walk the streets at night lest she is prepared to face danger.

Image (L-R): Streetlighting in City of eMalahleni's Mandela Street and City of George's Courtenay Street

\section{SIGNAGES}

Wayfinding system that includes a graphically consistent network of directional signs, street information panels with pedestrian-friendly maps, street names and building numbers/ names, street signs, signs in shopping malls and railway stations, etc., make it safer and easier for people of all abilities to navigate the city. Signs provide valuable information to city inhabitants and visitors. Lack of them can be dangerous especially for women if they lose direction and go on the ask for assistance from a person with malicious intent.

Most of the signages in all six cities are in symbols and the least are in words to give instructions or offer information to all people. It has been found that the use of symbols helps in providing a universal mode of communication so that even international visitors and illiterate members of our communities can understand the signs. Among the six cities, only the City of George has pedestrian-friendly maps, and the cities of eMalahleni, eMfuleni, Motlasane, Polokwane and uMhlathuze have none, but sometimes have boards showing directions of public offices or amenities. At most, it is difficult to navigate without getting lost. The streets are named with irregularities which make it difficult to identify the street names especially on intersections where one would want to see the road name to decide on a route to take. This situation is more pronounced in the city of uMhlathuze and the city of Polokwane. They are almost cities on 'mute' as they do not speak to the people. This poses a navigation challenge, especially for vulnerable women and girls who are new to the city and do not have a navigation device to assist them to find a way around.

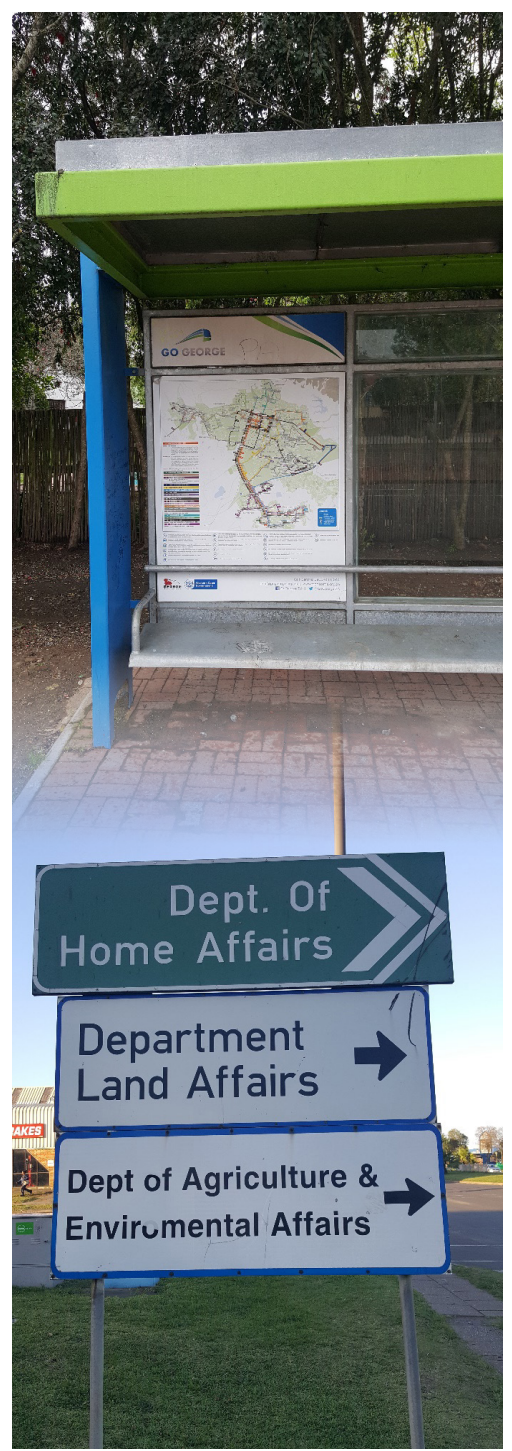

Image: Pedestrian-friendly maps in Meade Street and Boards showing the direction of offices in City of uMhlathuze's Bullion Blvd. 


\section{FOOTPATH'S AVAILABILITY, ACCESSIBILITY, AND USABILITY}

We are all pedestrians: on any given day - at a minimum - we begin and end most trips on foot, yet due to a lack of attention to the needs of pedestrians in most of our cities, and a tendency to favour motorized transport, pedestrians are at risk of death, injury, and disability. The state of footpaths in all audited cities; eMalahleni, eMfuleni, George, Motlasane, Polokwane, and uMhlathuze, presents a hybrid of good and bad depending on which part of the city you are walking. On good parts, the footpaths are wide and well-paved. On the bad parts, there are no paved footpaths and in some instances, the surface is so rugged that it's almost impractical for a wheelchair-bound person and mothers pushing baby prams to move. Obstructions on footpaths are a common sight especially in the CBD and downtown areas of these cities. The city of eMalahleni for example has this problem in abundance. This state of footpaths pose risk to women pushing prams with children, elderly women, and also people living with disabilities who are not at ease to move in such spaces.
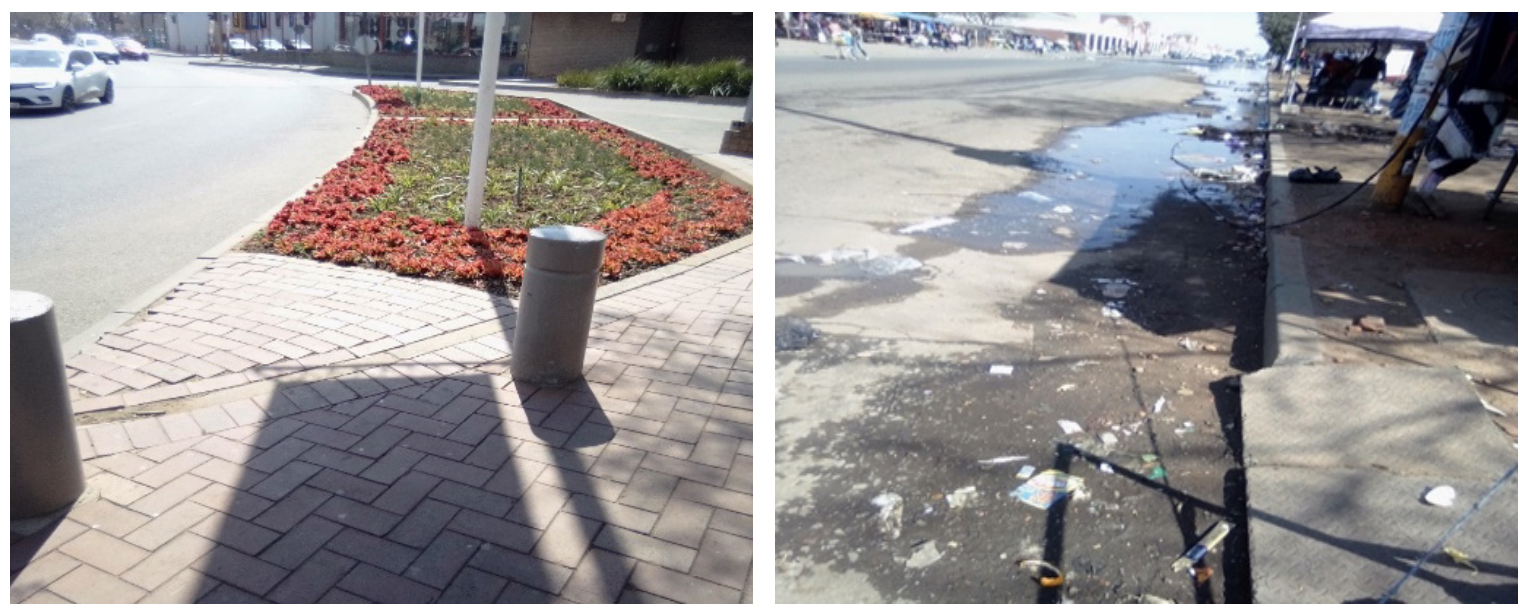

Image: Hybrid of the good and bad state of footpaths/ side walkways in the City of eMfuleni

\section{EMERGENCY HELP CONVENIENCE, INFORMAL SURVEILLANCE, POLICING AND MUGGING}

Public emergencies services are provided by the local governments in South African cities. The primary emergency service functions provided by local governments are police, fire, and emergency medical services. In addition, infrastructure such as public phones is valuable in accessing emergence help services in the city. The city safety audit examined public safety and perception of rescue within the CBD areas of all six cities. There are no identifiable public phones in all audited cities. There is adequate police visibility in the city of George, and very little to moderate police presence in other cities, with eMhlathuze and Polokwane representing cities with the least police presence. The police presence is mostly on vehicles and hardly any police officer is seen walking on the streets across all six cities. The experience shows that there are people generally in the CBD, shopping malls, and Downtown areas of these cities which form a relatively high level of informal surveillance during the day i.e., people walking and standing on the streets and also surveillance cameras in front of business properties during the day. This reduces crime such as mugging and pickpocketing hence making it feel safe for women and girls to walk and do business around the city.
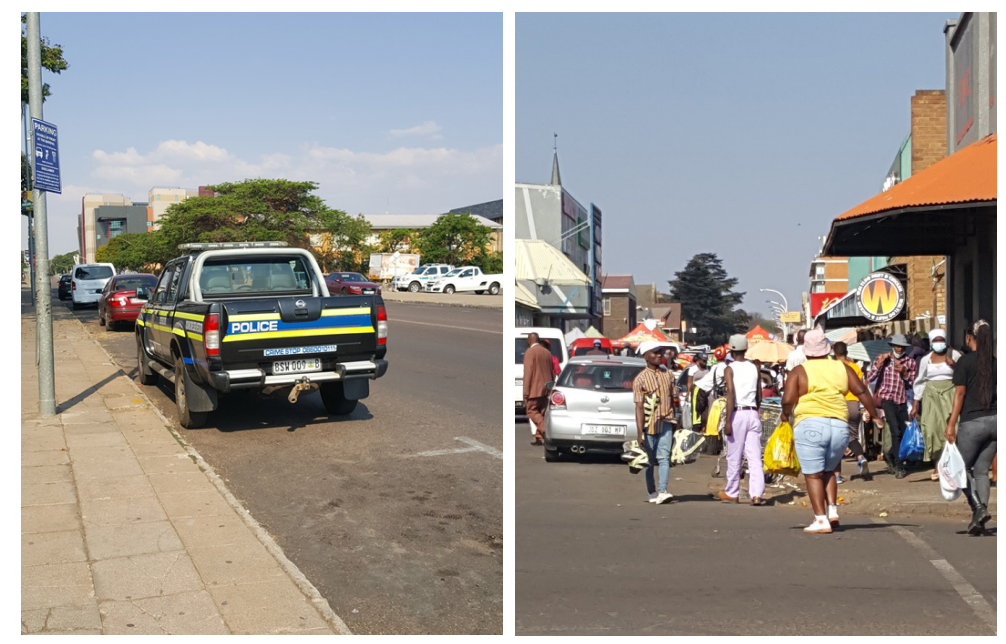

Image: Informal surveillance from daily shoppers in City of eMalahleni's Escombe street and Police presence in City of Polokwane's Bodenstein Street. 
The general observation, however more pronounced in Emfuleni, George, and uMhlathuze, shows that the common group of women seen in the city center are informal traders, daily shoppers, or queueing at a public service building i.e., bank, post office, home affairs office, or clinic. Within shopping malls, more women were waiting and lingering. However, the presence of too many people on shop corridors can sometimes be chaotic and utilized by pickpocketers to commit a crime without being identified, especially in the absence of police on foot patrol. The opinion polls indicate that in areas where there is less police patrol and informal surveillance and at night muggers sometimes brandish weapons or merely threaten harm, especially to women and usually steal money, jewelry, cell phones, or other valuables.

\section{STREET CROSSING SAFETY.}

Crossing a street can be a very difficult task for older pedestrians, women pushing prams, and people living with disabilities in general. With increased age and potentially cognitive decline, older people take the decision to cross a street primarily based on vehicles' distance, and not on their speed. Safer places to cross include zebra crossings, traffic islands, footbridges, subways, and traffic lights. Except for the City of George which has numerous unsignalised pedestrian crossings, the other five cities have very few street unsignalised pedestrian crossings. Unsignalised pedestrian crossings typically consist of signs and painted road markings ('zebra crossings'). Pedestrians are meant to have right of way over vehicles, but in some observed cases, in cities like eMalahleni, Motlasane, and uMhlathuze, motorists sometimes choose not to stop for pedestrians to cross. This gives unsignalised pedestrian crossings few benefits and may render them a hazard to women pushing prams, elderly people, and people living with disabilities in general.
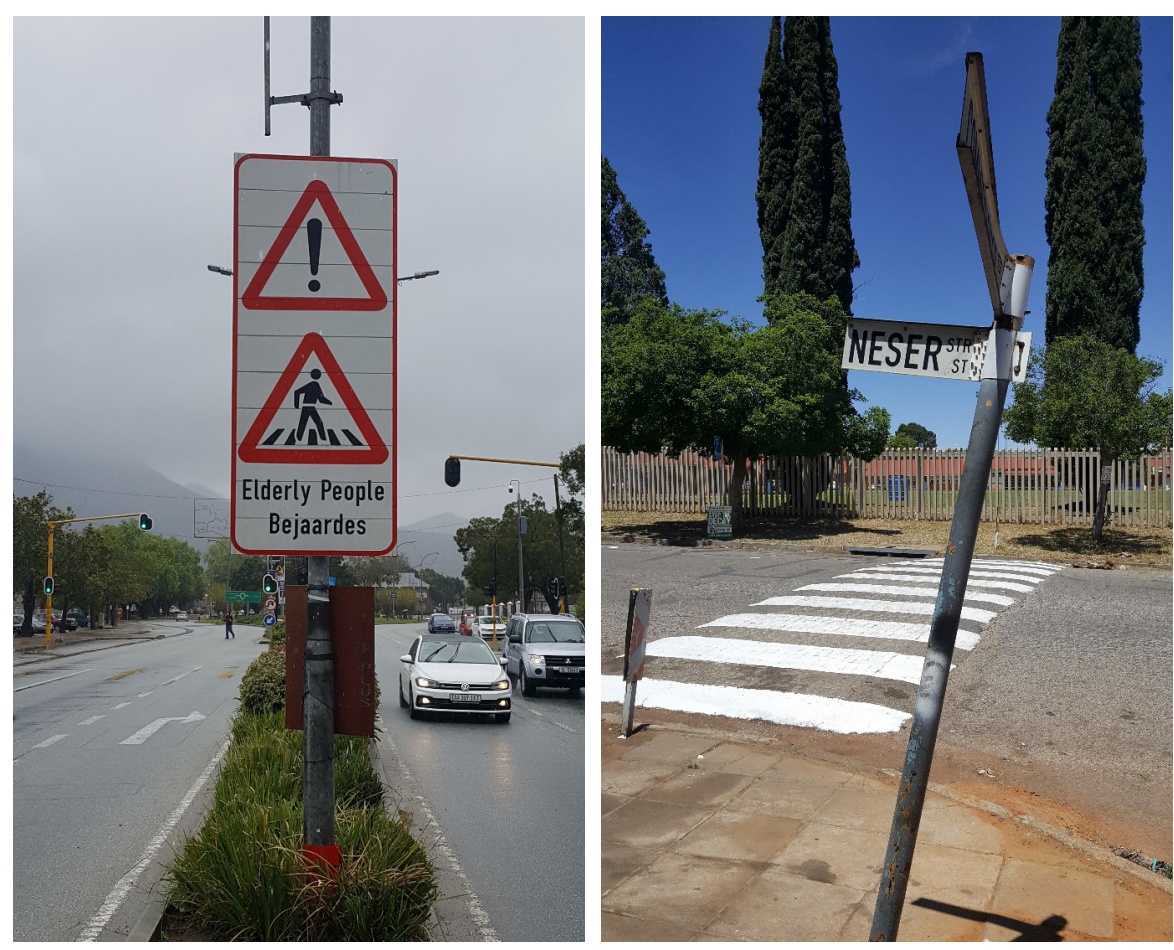

Image: City of George's York Street and City of Motlasane's Neser Street.

\section{CONCLUSION AND RECOMMENDATION}

The safety audit was conducted in six cities to investigate the street lighting, sagnages, footpaths condition, emergence service convenience, the potentiality of street mugging, and street crossing among others. The general finding was that across these cities, certain parameters were better than others depending on where and when you are in the city. It is relatively safer in the uptown area of the city than the $\mathrm{CBD}$ and downtown area. It is safer to be in the city during the day than in the evening or at night. However, it must be stressed that the degree of safety among these cities is not universal; it differs from one city to another.

Studies have shown that darkness results in a large number of crashes and fatalities, especially those involving pedestrians; pedestrian fatalities are 3 to 6.75 times more likely in the dark than in daylight. Criminality targeted at women has also been identified as rife in cities or parts of cities with poor illumination at night. This pertains to a potential physical attack upon a woman on a public street at night and the taking of money and other possessions. The audit has shown a strong connection between better lighting and the feeling of safety by women. It is therefore important to have good lighting uniformly distributed across the city. The maintenance of lighting should also be prioritized.

Road crash fatality data reveals that approximately $35-40 \%$ of road deaths in South Africa are pedestrian deaths. Most pedestrian crashes occur while the pedestrian is attempting to cross the road. Walking is integral to the livability and sustainability of our cities and should regain its place as a safe, convenient, and pleasant option for most trips. Through effective planning and engineering, cities can make roads safer for pedestrians. This could include: Careful consideration of pedestrian needs in road planning; Providing continuous footpaths, wide enough to support existing pedestrian traffic, on both sides of the road; Safer pavements offering protection from vehicles and bad road and weather conditions; Providing pedestrian holding areas at 
the roadside, at each intersection, where pedestrians can wait together before crossing the road; Zebra strips/crossings [called block pedestrian crossings] with stop lines for vehicles in areas where many pedestrians need to cross, traffic islands, footbridges, subways and traffic lights among other considerations. Pedestrian crossing design has the potential to shape pedestrian behaviour, while guiding people toward the safest possible route.

There is a need to recognize that safety is a fundamental right of living in a city and that, while a multitude of actors and sectors have responsibilities for creating safer communities, ultimately the state's responsibility is to guarantee the right of all inhabitants to be safe. The condition of footpaths in the CBD and downtown is below average. Most footpaths have obstructions - either it is street vendors or retrofitted infrastructure on the footpath. It was noticed that during peak hours, pedestrian footpath space is limited for pedestrians and also increases the chances of road accidents. Regulation and proper planning to remove and realign these obstructions will help to curb this problem. Footpaths with cracks or uneven surfaces and damage curbs must be repaired. The problem of obstructions built on footpaths is a symptom of incompetence from the employees or contractors who were tasked to do that job. It is therefore important to employ or contract qualified and competent personnel and contractors to avoid such blatant errors.

The audit has shown police presence is very low across most of the cities. Regular safety audits can be used to ensure that updated data is available for different parameters so that improvements can also be done on a regular. Since the streets become so male-dominated after dark and women do not feel comfortable; more visible security or police officers would be of utmost help to people who walk the streets to and from work after its dark especially women.

There must be recognition that the city is experienced differently by females and males, therefore gender should be mainstreamed throughout the guidelines and incorporated in each of the local governance and safety principles. Urban safety and security must be enhanced through effective urban planning, design, and governance from a gender perspective in cities. This intel, the mandatory incorporation of gender data as a prerequisite for one safety plans and policies. Municipalities' integrated development plans (IDPs) should define urban safety as a strategy that goes hand-in-hand with gender and should be mainstreamed in urban policy and governance.

Both safety and gender are cross-cutting issues and should be mainstreamed in all levels of governance and areas of competencies as a condition for sustainable development. The institutionalization of gender mainstreaming and gender equality in urban safety and crime prevention strategies requires more traction. As a result, this will help address the deeprooted social norms of gender-based violence and insecurity towards women and girls. Furthermore, women and girls must systematically be involved in the diagnosis of the safety of their city, from an intersectional approach.

When it comes to poor policing capacity in the majority of these cities, one way that they can accomplish doing more with less is through higher levels of social capital and cohesion. There must be a stronger effort to systematically include inhabitants in the design and planning of their cities to encourage a sense of belonging, build a shared identity, and (re)appropriate public spaces. Involving the community at an early stage (through citizens' committees for example) will result in a sense of ownership, connectedness, shared values, and responsibility of the process to make the city safer and support social cohesion. This does not only multiply the efforts of city authorities to improve personal security, but it also helps define security in ways that are more meaningful to residents.

South Africa has no shortage of sound policies and plans for women's safety in cities i.e. the vision 2030 of the National Development Plan states that in 2030 , people living in South Africa should feel safe at home, at school, and work, and enjoy a community life free of fear. Women should walk freely in the streets and children play safely outside. The current White Paper on Safety and Security advocates a developmental approach to creating safer communities through addressing risk factors on different levels and integrated planning and implementation by the government, informed by a sound knowledge base and active community participation. The Integrated Urban Development Framework (IUDF) presents urban safety as a cross-cutting issue for urban development and governance. It highlights the urban concentration of violence and crime in South Africa, as well as the consequent need for an urban approach, as part of the national response to making the country safer. The IUDF further emphasizes safety in public spaces as an essential ingredient for creating liveable and prosperous cities.

However, despite these plans and policies, cities are lagging noticeably behind their ambitions to create an urban environment that is safe for women. Implementation of policies remains a big challenge. The increased interest in reaching gender equity in women's safety will strengthen the implementation impetus for these policies and plans. Significant to succeed against the challenge of implementation will be to take an overarching approach to women safety issues rather than a fractured one, and for cities to work with women rather than seeking to direct them.

With South Africa's fast-growing urban population, it is glaring that our urban communities require services within walking or cycling reach within cities. This has extensive infrastructure implications and, in some cases, overwhelm existing infrastructure which has worsened the state of our urban infrastructure. Coupled with lack of maintenance, most of the infrastructure like paved footpaths and safe pedestrian crossings or footbridges are in a dire state, rendering them unsafe for use, especially for women. The next decade must be one of rapid urban infrastructure development to meet the basic safety needs of city residents, particularly women. This will also require better management of existing infrastructure. 
City planning can for instance consider the physical infrastructure (for example, the safety of public spaces), access to public services, and other issues that may be relevant from a safety and security perspective. Furthermore, the planning process itself can be an opportunity to engage actors at various levels of government and responsibility with local communities to gather data for a better understanding of relevant risks and flows (and effects of policies), while promoting greater community ownership of the final plan.

The general focal areas for consideration from the finding of this audit are only a broad framework. It must be acknowledged and highlighted that safety experiences are not universal across different cities, hence contextual application of any form of intervention is highly recommended.

Cities must determine for themselves the key areas that need attention. Local municipalities should undertake safety audits with communities to establish safety needs and strategies. They should also report on designs aimed at addressing the safety of women and other vulnerable groups, as well as develop comprehensive safety plans and allocate corresponding budgets for implementation. Furthermore, cities must be held accountable for adopting a gender perspective in their safety policies and plans. Nevertheless, it must also be suggested many cities interventions should not focus only on local dynamics without a broader understanding of how some issues are connected to the prevailing state of affairs across the country and other cities.

Targeted interventions should be supported by consistent, long-term urban safety policies that are comprehensive, cross-sectoral, and set out the competencies, responsibilities, and accountability of local governments, as well as other spheres of government and other role-players such as civil society. 
Notes 